\title{
Toxicity effect of colloidal silver nanoparticles on fertilization capacity and reproduction success of rainbow trout (oncorhynchus mykiss)
}

\begin{abstract}
Due to the increasing use of nanomaterials in human daily life and probable release of these substances into the environment, the present study investigated the effect of the presence of colloidal silver nanoparticles (cAgNPs) in the aquatic environment on the reproduction of rainbow trout as a model aquatic organism. Chemically produced cAgNP colloid was purchased from Pars Nano-Nasb (Iran) and contained 4000mg/l silver nanoparticles in deionised water. According to the transmission electron microscopy (TEM) results, the Count median diameter of nanoparticles in the colloid was $6.47 \mathrm{~nm}$. Rainbow trout eggs and sperm were obtained by stripping the fish. For each treatment 500 eggs were completely mixed with $1 \mu 1$ of milt. In the control group $(0 \mathrm{mg} / \mathrm{l} \mathrm{cAgNPs})$, water was added to activate sperm motility and leading to fertilization. To evaluate effect of AgNPs on fertilization, water containing three concentrations of cAgNPs including $0.1,0.01$ and $0.001 \mathrm{mg} / \mathrm{L}$ were added for sperm activation. Resulted eggs were incubated in a recirculation incubator system at a constant temperature of $10^{\circ} \mathrm{C}$. Survival rate from 24 hours post-fertilization to the eyed-stage (eyeing rate), survival from eyed-stage to hatching (hatching rate), and survival from hatching to the end of yolk sac absorption were monitored. The results showed that the eyeing rate of all cAgNPs exposed treatments were same as the control; while the hatching rates of all cAgNPs exposed treatments was significantly lower than the control $(0>0.001>0.01>0.1 \mathrm{mg} / \mathrm{l})$. A significant decrease was observed in the survival at the end of yolk-sac absorption only in the $0.1 \mathrm{mg} / \mathrm{l} \mathrm{cAgNPs}$ group. Also significant and dose-dependent decrease in duration of sperm motility was observed after in vitro sperm exposure to $\mathrm{cAgNPs}(0>0.001>0.01>0.1 \mathrm{mg} / \mathrm{l})$. According to these results, presence of 0.1 $\mathrm{mg} / \mathrm{l} \mathrm{cAgNPs}$ in the water environment can affect the fertilization and reproduction success of rainbow trout. Thus, the presence of silver nanoparticles in the aquatic environment can interfere with fish reproduction and thereby fish populations will be at risk.
\end{abstract}

Keywords: Aquatic Nanotoxicology, Colloid, Rainbow trout, Silver nanoparticles, Sperm Motility, Eyeing Rate, Hatching Rate
Volume I Issue I - 2014

\author{
Seyed Ali Johari \\ Fisheries Department, University of Kurdistan, Iran
}

Correspondence: Seyed Ali Johari, Fisheries Department, University of Kurdistan, ZIP Code: 66177-15175, P.O. Box 416, Sanandaj, Kurdistan, I. R. Iran, Tel 98-9|26268409, Fax 988716620550Email a.johari@uok.ac.ir

Received: August 30, 2014 | Published:September 05, 2014
Abbreviations:cAgNPs, Colloidal Silver Nanoparticles; CASA, Computer Assisted Sperm Analyzer; NTA, Nanoparticle Tracking Analysis; TEM, Transmission Electron Microscopy

\section{Introduction}

Although the development of modern technologies will provide better opportunities for human life and health, on the other hand, these technologies are usually causing damage to the environment. Aquatic ecosystems as a part of the environment are constantly exposed to a variety of physical and chemical pollutants, which amount of these contaminants is increasing with the development of technology. In this respect, aquatic toxicology is responsible for studying the effects of organic and inorganic pollutants on aquatic organisms. Although nanotechnology has been used for many years in human life, but its scientific understanding and development has greatly expanded in recent decades; and it is anticipated that many human needs to be answered through this technology over the coming years. Based on the statistics obtained from thirty countries of the world, the number of consuming products by human being in which the nanomaterials are used, has increased from 54 in 2005 to 1628 in 2013 and it is predicted that this number would be rapidly increasing in future years too. ${ }^{1}$ According to forecasts, the market of products containing nanomaterials will be worth $\$ 1$ trillion by 2015 .

Silver nanoparticles due to the unique features such as antimicrobial properties, are considered as the most important and most widely used man-made nanomaterials and are used in the different types of products such as cosmetics, detergents, clothes, shoes, food additives, as well as coating on respiratory masks, water filters, phones, laptops, toys, and home water treatment systems (such as Aquapure, Kinetico and QSI-Nano). One of the types of products that contain silver nanoparticles today as antimicrobial disinfectant and are widely available on the market, colloid silver nanoparticles. The colloidal silver nanoparticles (cAgNPs), is one of the antimicrobial products which is widely available on the market. For example, in Iran a variety of silver nanoparticle colloids are produced with brand names such as "NanoCid", "NanoNip", "NanoFarm", "NanoClean" NanoSilveral" etc. According to estimates 63 tons of silver nanoparticles released into the aquatic ecosystems annually. ${ }^{3}$ Moreover, the concentration range of silver nanoparticles in aquatic biomes has been estimated as 0.03 to $0.32 \mu \mathrm{g} / 1 .{ }^{4}$ Thus, understanding the potential effects of this nanomaterial on aquatic organisms is very important. Because of the external fertilization in most of fish, gametes may be exposed to contaminants in the water, which could affect their reproductive success. Because the duration of sperm motility in fish is very short (for example, between 30 and 60 seconds and sometimes a little more in rainbow trout), fertilization should occur as soon as possible after the release of gametes in the aquatic environment; therefore if external factors affect this process, fertilization success changes subsequently. In a study it showed that concentrations higher than $1 \mathrm{mg} / \mathrm{l}$ of methyl 
mercury reduce the viability of trout sperm..$^{5}$ Another study also was showed reduction of the fertilization ability of rainbow trout sperm after exposure to $10 \mathrm{mg} / \mathrm{l}$ of mercury or cadmium. ${ }^{6}$ Several indices are used to measure the strength of sperm fertilization, for example: the speed and duration of sperm motility, fertilization rate and hatchability. ${ }^{7}$ In many studies, the sperm motility have been used as an accurate and sensitive biological indicator to assess the impact of pollutants on sperm cells and computer software such as CASA is used to analyze motility data. ${ }^{8}$ Although this is a very quick and simple method for measuring the toxicity, it could not explicitly show the success rate of fertilization by sperm. ${ }^{9}$ Therefore, the use of other indicators (fertilization rate, hatching rate, etc.) is more efficient to assess the impact of environmental pollutants on fish reproduction capability. ${ }^{10,11}$

While several studies in recent years have focused on the toxic effects of silver nanoparticles in different aquatic organisms (e.g. fish. ${ }^{12}$ daphnia. ${ }^{13}$ algae. ${ }^{14}$ mussels. ${ }^{15}$ etc.), however, to our knowledge there is no report on the effects of nano-silver on fish reproduction. Accordingly, this study examined the effect of colloidal silver nanoparticles on fertilization capacity and reproduction success of rainbow trout (Oncorhynchus Mykiss).

\section{Materials and methods}

\section{Nanomaterial and characterization}

This study used colloidal silver nanoparticles (cAgNPs) which are commercially available in the Iranian Market. This commercial nanomaterial was chosen because we wanted to study on a material that is currently marketed and most likely is included in consumer products, and therefore can be relevant for future risk assessments. Detailed characterizations of this product can be found in our previous study. ${ }^{12}$ and are briefly shown in (Table 1). Figure 1 shows TEM image of the particles (prepared by Hitachi H-7100FA). Also the hydrodynamic diameter distribution of silver particles in colloid was measured by using NTA system (model LM10-HS) it was $63 \pm 24 \mathrm{~nm}$.

Table I Characterizations of silver nanoparticles used (derived from Johar et al., 2013 [12])

\begin{tabular}{|c|c|c|}
\hline & \multirow{2}{*}{$\begin{array}{l}\text { Nanocid L2000 } \\
\text { Nano Nasb Pars Co., } \\
\text { Ltd (Tehran, Iran) }\end{array}$} \\
\hline Manufacturer & & \\
\hline Appearance & Size & Yellowish-brown Colloid \\
\hline $\begin{array}{l}\text { Manufacturer } \\
\text { Information } \\
\text { Information from } \\
\text { TEM* }\end{array}$ & $\begin{array}{l}\text { Size } \\
\text { Concentration }(\mathrm{mg} / \mathrm{l}) \\
\text { Max. Diameter }(\mathrm{nm}) \\
\text { CMD* }(\mathrm{nm}) \\
\text { GMD* }(\mathrm{nm}) \\
\text { GSD* } \\
\text { Shape }\end{array}$ & $\begin{array}{l}16.6 \\
4000 \\
129 \\
6.47 \\
12.65 \\
1.46 \\
\text { Spherical }\end{array}$ \\
\hline & Zeta potential $(\mathrm{mV})$ & $-53.33 \pm 7.86$ \\
\hline $\begin{array}{l}\text { Information from } \\
\text { DLS* }\end{array}$ & $\begin{array}{l}\text { Hydrodynamic } \\
\text { diameter }(\mathrm{nm})\end{array}$ & 54.8 \\
\hline $\begin{array}{l}\text { Information from } \\
\text { ICP-AES* }\end{array}$ & Concentration (mg/l) & 3980 \\
\hline & $\mathrm{pH}$ & 2.4 \\
\hline
\end{tabular}

* CMD: Count Median Diameter; GMD: Geometric Mean Diameter; GSD: Geometric Standard Deviation; TEM: Transmission Electron Microscope; DLS: Dynamic Light Scattering; ICP-AES: Inductively Coupled Plasma-Atomic Emission Spectroscopy

\section{In vivo experiments}

The ova and milt of five male and five female rainbow trout were used for this study. To avoid the influence of genetic differences between selected females on test results, all ova were pooled right prior to fertilization and then about 500 ova were taken for each treatments. The coelomic fluid was separated by a mesh prior to mixing the ova and milt. For fertilization of each batch of ova, $1 \mu \mathrm{l}$ of milt of each male was added and mixed well with ova (a total of $5 \mu 1$ milt for each 500 ova per treatment). To activate sperm motility and fertilization in the control group, normal water (without any chemicals) with a temperature of $10^{\circ} \mathrm{C}$ was used. In order to evaluate the effect of cAgNPs on the fertilization capacity, in the other treatments of this study water containing different concentrations of cAgNPs $(0.001,0.01,0.1 \mathrm{mg} / \mathrm{l})$ was used to induce sperm motility. After the end of fertilization, the eggs were washed several times with normal water to remove any extra sperm. Then the eggs were allowed to absorb water for $60 \mathrm{~min}$. Obtained eggs from different treatments were incubated in a recirculation incubator to pass embryonic stages. The water temperature of this incubator was kept constant at $10^{\circ} \mathrm{C}$ by an automatic cooling system. In order to reduce the concentration of waste products in water (especially ammonia compounds), 10 percent of water were replaced daily. Required oxygen for the eggs was supplied by air stones connected to an air pump. Various indices were calculated during the incubation period, including survival rate from 24 hours post-fertilization to the eyed-stage (eyeing rate), survival from eyed-stage to hatching (hatching rate), and survival from hatching to the end of yolk sac absorption.

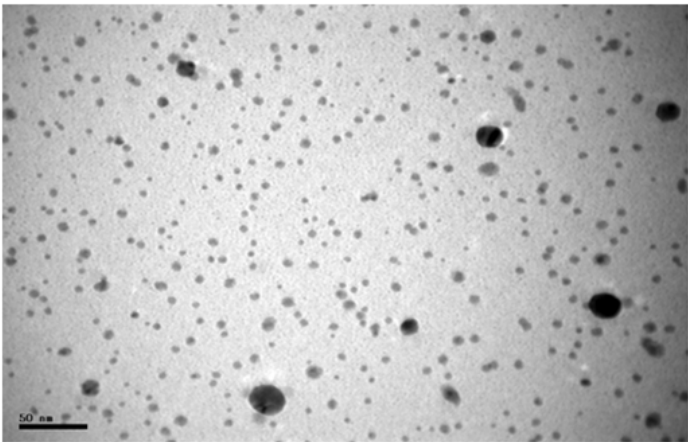

Figure I TEM micrographs of colloidal silver nanoparticles.

\section{In vitro experiments}

After performing all fertilization processes related to in vivo experiments, in a complementary experiment, to evaluate the effect of silver nanoparticles on rainbow trout sperm cells in vitro, duration of sperm motility was evaluated following exposure to normal water (control group) or water containing $0.001,0.01$ and 0.1 $\mathrm{mg} / \mathrm{l} \mathrm{cAgNPs}$. For this purpose, for each of the above treatments the milt sample of three male was used (each one as a replicate). First, $1 \mu 1$ of semen was dropped onto a clean-dry slide and after putting a cover slip on it and putting it under a preset light microscope, $1 \mu \mathrm{l}$ of activator water (from control or treatments) was poured to activate spermatozoa. Then the duration of spermatozoa motility was assessed from the moment of contact with the water until the end of mobility of about $90 \%$ of spermatozoa. ${ }^{16}$

\section{Statistical analysis}

Statistical analysis of data was performed using SPSS and normality of the data was evaluated by Kolmogorov-Smirnov test. Statistical analyses were carried out using standard ANOVA techniques, followed by Duncan's significant difference test. Differences were statistically significant when $\mathrm{p}<0.05$.

\section{Results}

The results of reproductive success indices of rainbow trout following fertilization the sperm and ova in water containing different concentrations of silver nanoparticles are briefly shown in (Table 
2). Based on these results, no significant difference was observed in the case of eyeing rate of eggs between different concentrations of $\mathrm{cAgNPs}$ and the control group (eyeing rate of $0=0.001=0.01=0.1$ $\mathrm{mg} / \mathrm{l})$. On the other hand, the hatching rate in the control group was significantly higher than that of the exposed treatments to cAgNPs and as shown in (Table 2), with increasing the concentrations of silver nanoparticles, the percentage of hatching eggs showed a significant decrease (hatching rate of $0>0.001>0.01>0.1 \mathrm{mg} / \mathrm{l}$ ). Although survival rate from hatching to the end of yolk sac absorption in the treatments containing low concentrations of silver nanoparticles was similar to the control group, however this amount was significantly lower in the treatments containing $0.1 \mathrm{mg} / \mathrm{l}$. Measurement results of duration of spermatozoa motility of rainbow trout after activation with water containing different concentrations of silver nanoparticles are shown in (Table 3). According to these results, the duration of sperm motility in the control group was significantly longer than that of spermatozoa cells that had been activated with water containing silver nanoparticles. Also, with increasing concentration of silver nanoparticles, duration of sperm motility was reduced $(0>0.001>$ $0.01>0.1 \mathrm{mg} / \mathrm{l})$.

Table 2 The indices of reproductive success of rainbow trout, following fertilization of sperm and ova in water containing different concentrations of colloidal silver nanoparticles

\begin{tabular}{|c|c|c|c|c|}
\hline \multicolumn{4}{|c|}{$\begin{array}{l}\text { Concentrations of silver nanoparticles in water } \\
(\mathrm{mg} / \mathrm{l})\end{array}$} & \\
\hline 0.1 & 0.01 & 0.001 & 0 (control) & \\
\hline $55.91 \pm 0.29 \mathrm{a}$ & $54.79 \pm 1.43^{a}$ & $\begin{array}{l}55.26 \pm \\
1.08^{\mathrm{a}}\end{array}$ & $\begin{array}{l}56.72 \pm \\
0.54^{\text {a }}\end{array}$ & $\begin{array}{l}\text { Eyeing rate } \\
\text { of eggs }\end{array}$ \\
\hline $29.38 \pm 2.63^{d}$ & $33.91 \pm 0.86^{c}$ & $\begin{array}{l}35.50 \pm \\
0.58^{\mathrm{b}}\end{array}$ & $\begin{array}{l}40.56 \pm \\
1.38^{\mathrm{a}}\end{array}$ & $\begin{array}{l}\text { Hatching } \\
\text { rate of eyed } \\
\text { eggs }\end{array}$ \\
\hline $54.39 \pm 0.8 \mathrm{I}^{\mathrm{b}}$ & $56.66 \pm 1.33 \mathrm{a}$ & $\begin{array}{l}57.69 \pm \\
0.5 I^{\text {a }}\end{array}$ & $\begin{array}{l}57.18 \pm \\
0.64^{\mathrm{a}}\end{array}$ & $\begin{array}{l}\text { Survival } \\
\text { rate from } \\
\text { hatching } \\
\text { to the end } \\
\text { of yolk sac } \\
\text { absorption }\end{array}$ \\
\hline
\end{tabular}

Table 3 Duration of spermatozoa motility of rainbow trout after activation with water containing different concentrations of colloidal silvernanoparticles

\begin{tabular}{|c|c|c|c|c|}
\hline \multicolumn{4}{|c|}{$\begin{array}{l}\text { Concentrations of silver nanoparticles in } \\
\text { water }(\mathrm{mg} / \mathrm{l})\end{array}$} & \\
\hline 0.1 & 0.01 & 0.001 & 0 (control) & \\
\hline $56.33 \pm 12.09$ & $\begin{array}{l}69.00 \pm \\
28.16\end{array}$ & $\begin{array}{l}71.00 \pm \\
24.82\end{array}$ & $\begin{array}{l}82.33 \pm \\
26.57\end{array}$ & $\begin{array}{l}\text { Duration of } \\
\text { spermatozoa } \\
\text { motility (seconds) }\end{array}$ \\
\hline
\end{tabular}

\section{Discussion}

According to the results of in vitro experiments, the toxic effects of silver nanoparticles on rainbow trout sperm cells is evident clearly as a concentration-dependent decrease in duration of sperm motility. In this regard, also the results from in vivo experiments were often concentration-dependent and the only exception was the percentage of eyeing rate of eggs. Therefore when testing the effects of toxic chemicals on fish fertilization success, although the sperm motility assay is a rapid, simple and striking method, but the use of other indicators, such as examination of fertilization rate, eyeing rate, hatching rate and survival rate of larvae, can better show prediction of the effects of pollutants on fertilization capacity of the egg by the sperm. More studies are needed to understand the mechanism by which the silver nanoparticles affect the fertilization of the egg and sperm of fish. Although no information is available about the effect of silver nanoparticles on fertilization and reproduction of fishes, but in a study about aquatic organisms, it has been shown that although fertilization capability of sea urchin sperm is not influenced by silver nanoparticles, their offspring exhibit morphological abnormalities. ${ }^{17}$ In few studies which have been conducted on mammalian sperm, signs of toxic effect of silver nanoparticles are observed. For example in a study by Moretti et al. ${ }^{18}$ it has been shown that silver nanoparticles exerted a significant dose-dependent effect on motility and viability of human spermatozoa. ${ }^{19}$ Also Asare et al..$^{20}$ indicated toxic effect of silver nanoparticles against human testicular embryonic carcinoma cell line as well as primary testicular cells of mice. ${ }^{20}$ In another study by Gromadzka-Ostrowska et al. ${ }^{19}$ it have been shown that injection of rats with nano silver cause a size-dependent, dose-dependent and time-dependent decrease of the epididymal sperm count as well as increase in the level of DNA damage in germ cells. ${ }^{20}$

\section{Conclusion}

Totally, the results of this study indicate that silver nanoparticles influence on trout fertilization and also on survival of larvae in stages after fertilization. Therefore more attentions are needed in relation to the prevention of waste containing silver nanoparticles to aquatic ecosystems and developing environmental standards for determining permissible levels of nanomaterials in aquatic ecosystems.

\section{Acknowledgements}

This research supported by a grant from the University of Kurdistan (Grant N0.4-43627).

\section{Conflicts of interest}

None.

\section{References}

1. Woodrow Wilson Database Nanotechnology consumer product inventory. Last checked on 6 June 2014. 2014

2. Laban G, Nies LF, Turco RF et al. The effects of silver nanoparticles on fathead minnow (Pimephales promelas) embryos. Ecotoxicology. 2010;19(1):185-195.

3. Keller AA, McFerran S, Lazareva A, Suh S Global life cycle release of engineered nanomaterials. Journal of Nanoparticle Research. 2013;15:1692.

4. Batley GE, Kirby JK, McLaughlin MJ Fate and risks of nanomaterials in aquatic and terrestrial environments. Acc Chem Res. 2013;46(3):854-862.

5. McIntyre JD Toxicity of methyl mercury for steelhead trout sperm. Bull Environ Contam Toxicol. 1973;9(2):98-99.

6. Dietrich GJ, Dietrich M, Kowalski RK et al. Exposure of rainbow trout milt to mercury and cadmium alters sperm motility parameters and reproductive success. Aquat Toxicol. 2010;97(4):277-284.

7. Rurangwa E, Roelants I, Huyskens G et al. The minimum effective spermatozoa: egg ratio for artificial insemination and the effects of mercury on sperm motility and fertilization ability in Clarias gariepinus. Journal of Fish Biology 53(2), pp. 1998;402-413.

8. Kime DE, Ebrahimi M, Nysten K et al. Use of computer assisted sperm analysis (CASA) for monitoring the effects of pollution on sperm quality of fish; application to effects of heavy metals. Aquatic Toxicology. 1996;36:223-237.

9. Bromage NR, Roberts RJ Broodstock Management and Egg and Larval Quality. Oxford: Blackwell. 1995

10. Hall LW, Horseman LO, Zeger S Effects of organic and inorganic chemical contaminants on fertilization, hatching success, and prolarval survival of striped bass. Archives of Environmental Contamination and Toxicology. 1984;13:723-729. 
11. Khan AT, Weis JS Effects of methylmercury on sperm and egg viability of two populations of killifish (Fundulus heteroclitus). Environ Res. 1987;16:499-505

12. Johari SA, Kalbassi MR, Soltani M, Yu IJ Toxicity comparison of colloidal silver nanoparticles in various life stages of rainbow trout (Oncorhynchus mykiss). Iranian Journal of Fisheries Sciences. 2013;12(1):76-95.

13. Asghari S, Johari SA, Lee JH et al. Toxicity of various silver nanoparticles compared to silver ions in Daphnia magna. J Nanobiotechnology 10 doi: 10. 2012;1186/1477-3155-10-14.

14. Ribeiro F, Gallego-Urrea JA, Jurkschat $\mathrm{K}$ et al. Silver nanoparticles and silver nitrate induce high toxicity to Pseudokirchneriella subcapitata, Daphnia magna and Danio rerio. Sci Total Environ. 2013;466-467:232-241.

15. Gagne F, Auclair J, Turcotte P et al. Sublethal effects of silver nanoparticles and dissolved silver in freshwater mussels. $J$ Toxicol Environ Health A. 2013;76(8):479-490.
16. Billard R Effects of coelomic and seminal fluids and various saline diluents on the fertilizing ability of spermatozoa in the rainbow trout, Salmo gairdneri. J Reprod Fertil. 1983;68(1):77-84.

17. Gambardella C, Aluigi MG, Ferrando S et al. Developmental abnormalities and changes in cholinesterase activity in sea urchin embryos and larvae from sperm exposed to engineered nanoparticles. Aquat Toxicol. 2013;130-131:77-85.

18. Moretti E, Terzuoli $\mathrm{G}$, Renieri $\mathrm{T}$ et al. In vitro effect of gold and silver nanoparticles on human spermatozoa. Andrologia. 2013;45(6):392-396.

19. Gromadzka-Ostrowska J, Dziendzikowska K, Lankoff A et al. Silver nanoparticles effects on epididymal sperm in rats. Toxicol Lett. 2012;214(3):251-258.

20. Asare N, Instanes C, Sandberg WJ et al. Cytotoxic and genotoxic effects of silver nanoparticles in testicular cells. Toxicology. 2012;291(1-3):65-72. 